\title{
Genotypes and Phenotypic Characterization of Field Fusarium asiaticum Isolates Resistant to Carbendazim in Anhui Province of China
}

Yu Chen, Xue Yang, Chun-Yan Gu, Ai-Fang Zhang, and Tong-Chun Gao, Institute of Plant Protection and Agro-products Safety, Anhui Academy of Agricultural Sciences, Hefei 230031, China; Laboratory of Quality \& Safety Risk Assessment for Agro-Products (Hefei), Ministry of Agriculture, China; and Scientific Observing and Experimental Station of Crop Pests in Hefei, Ministry of Agriculture, China; and Ming-Guo Zhou, College of Plant Protection, Nanjing Agricultural University, Nanjing 210095, China

\begin{abstract}
Chen, Y., Yang, X., Gu, C.-Y., Zhang, A.-F., Gao, T.-C., and Zhou, M.-G. 2015. Genotypes and phenotypic characterization of field Fusarium asiaticum isolates resistant to carbendazim in Anhui province of China. Plant Dis. 99:342-346.

Fusarium asiaticum is a causal agent of Fusarium head blight (FHB) of wheat in the southern part of China. Carbendazim has been extensively used for controlling FHB for more than 30 years, leading to the widespread carbendazim-resistant isolates in all major wheat-producing provinces in China, especially in Anhui Province. F. asiaticum isolates were collected throughout Anhui Province between 2010 and 2012 to monitor their sensitivity to carbendazim. In total, 74 of 899 singlespore isolates $F$. asiaticum were found to be resistant to carbendazim. Resistant isolates were collected from all of the sampled sites except Hefei of Anhui Province. The overall frequency of carbendazim resistance was shown to be $8.2 \%$. Of the 74 isolates, 1,68 , and 5 had low resistance (LR), moderate resistance (MR), and high resistance (HR),

respectively, to carbendazim. Five types of point mutations (F167Y, E198L, E198K, F200Y, and E198Q) in the $\beta_{2}$-tubulin gene conferring resistance to carbendazim were detected in the field-resistant isolates with frequencies of $89.2,2.7,4.1,2.7$, and $1.4 \%$, respectively. The point mutations at codon 167,198 , or 200 of the $\beta_{2}$-tubulin gene were correlated with different levels of carbendazim resistance. Some of the sensitive and resistant isolates appeared to possess different biological characteristics; however, these might not be due to resistance. Because carbendazim resistance was generally widespread throughout Anhui Province, the sensitivity of $F$. asiaticum populations to carbendazim should be constantly monitored for the development of carbendazim resistance in natural populations.
\end{abstract}

Fusarium head blight (FHB) of wheat, also known as wheat scab, is a important disease of cereals and occurs in cereal production worldwide (2). It is a devastating disease of wheat, which can cause severe losses in epidemic years and is a big problem for the wheat industry worldwide (10). In China, the middle and lower reaches of the Yangtze River, Jianghuai Valley, southern winter wheat region, and the northeast (planting spring wheat) region are the main areas affected by FHB. In areas where the climate is humid and favorable for FHB epidemics $(7,30)$, FHB could result in 5 to $40 \%$ loss of yield. There is the potential for further decreasing the grain quality as a result of mycotoxin production (deoxynivalenol and nivalenol) during the storage of grain $(5,12,23,25,28)$. To date, at least 11 phylogenetic species which belong to the Fusarium graminearum Schwabe species complex of B-trichothecene toxin producers were responsible for FHB disease $(10,15,30)$. In China, F. asiaticum O'Donnell, T. Aoki, Kistler \& Geiser sp. nov. and $F$. graminearum have been considered to be the major causal agents for FHB $(21,24,27,30)$. A previous study reported that $77.3 \%$ of the 299 collected $F$. graminearum complex isolates from different regions of China were confirmed to be $F$. asiaticum and another 68 isolates were identified as F. graminearum (32).

Application of benzimidazole fungicides during the wheat flowering stage was the sole effective measure for the control of FHB in the last three decades. However, the efficacy of this group of fungicides is decreasing due to the development of carbendazim resistance in the fungal population (8). Benzimidazole resistance

Corresponding authors: T.-C. Gao, E-mail: gtczbs@sina.com; and M.-G. Zhou, E-mail: mgzhou@njau.edu.cn

Y. Chen and X. Yang share joint first authorship for this work.

Accepted for publication 10 August 2014.

http://dx.doi.org/10.1094/PDIS-04-14-0381-RE

(C) 2015 The American Phytopathological Society has developed in many fungal species after this class of fungicides has been used for certain years and is always associated with point mutations in the $\beta$-tubulin gene that change the amino acid sequence at codons $6,50,165,167,198,200,241$, and 257 (18). However, a previous study has confirmed that the carbendazim resistance in $F$. graminearum was correlated with the point mutations in the $\beta_{2}$-tubulin gene (GenBank accession number FG06611.1), which is different from the formerly known $\beta$-tubulin gene (now called $\beta_{1}$-tubulin; GenBank accession number FG09530.1) (6).

Carbendazim, a common benzimidazole fungicide, has been used extensively for controlling FHB in Anhui Province for more than 30 years. However, failure of carbendazim to control FHB has been observed by farmers and is likely due to the development of carbendazim resistance during epidemic years (9-11). The frequency and distribution of resistance to carbendazim in F. asiaticum populations of Anhui Province are still unknown. Therefore, the objectives of this study were to (i) monitor the sensitivity of $F$. asiaticum to carbendazim in several wheat-growing regions of Anhui Province, (ii) amplify the whole fragment of the carbendazim resistance-related $\beta_{2}$-tubulin gene and determine whether different types of point mutation in the $\beta_{2}$-tubulin gene are conferring resistance to carbendazim, and (iii) compare the biological properties of the carbendazim-resistant and -sensitive isolates from Anhui Province. These results would be informative to both scientific researchers and local farmers to better understand the carbendazim resistance in $F$. asiaticum causing FHB and make decisions to effectively control this disease and manage carbendazim resistance.

\section{Materials and Methods}

Fungicide and media. Carbendazim fungicide was obtained from Shenyang Academy of Chemistry and Industry (Shengyang, China). It was dissolved in hydrochloric acid ( $\mathrm{HCl} ; 0.1 \mathrm{~mol} / \mathrm{liter})$ at $5 \mathrm{mg} / \mathrm{ml}$ as stock solution. Carbendazim stock solution was added to potato sucrose agar (PSA) when it had been cooled to approximately $50^{\circ} \mathrm{C}$. 
Isolation of $\boldsymbol{F}$. asiaticum. Wheat samples with symptoms of FHB were collected from different wheat fields in 55 fields of 10 sites, the major wheat-producing regions of Anhui Province. Diseased samples were collected between 2010 and 2012. In each field, 20 to 32 plants with symptoms of FHB were randomly collected, air dried, placed in paper envelopes, and stored at $-4^{\circ} \mathrm{C}$. Identification of $F$. asiaticum and $F$. graminearum species was performed according to a previous study (26). Water agar medium (1.8\% agar) was used to recover single-spore isolates. PSA was used for culturing the collected isolates and to determine the sensitivity to carbendazim. In all, 899 isolates of F. asiaticum were obtained from 1,332 samples.

Phenotypic characterization of carbendazim resistance in $\boldsymbol{F}$. asiaticum. The sensitivity of all these $F$. asiaticum isolates to carbendazim was determined by transferring plugs $(5 \mathrm{~mm}$ in diameter) from the edge of an actively growing colony ( 3 days old) to a series of PSA media amended with carbendazim at $0,1.4,50$, and $100 \mu \mathrm{g} / \mathrm{ml}$ and incubated at $25^{\circ} \mathrm{C}$ in the growth chamber for 3 to 4 days. There were three replicates for each concentration. Based on the colony growth at various concentrations of carbendazim, the isolates were classified into four different sensitivity phenotypes, including sensitive (S), low resistance (LR), moderate resistance (MR), and high resistance (HR). Isolates with a completely inhibited growth on PSA plates amended with carbendazim at 1.4, 50, and $100 \mu \mathrm{g} / \mathrm{ml}$ were considered to be $\mathrm{S}, \mathrm{LR}$, and MR isolates, respectively, and the isolates which were able to grow with carbendazim at $100 \mu \mathrm{g} / \mathrm{ml}$ were considered to be HR isolates (31).

Biological properties of carbendazim-sensitive and -resistant isolates. Mycelial growth. In all, carbendazim-resistant and 10 carbendazim-sensitive isolates were used to characterize biological properties. The mycelial plugs (5 $\mathrm{mm}$ in diameter), which were arbitrarily selected from the collected isolates, were transferred to PSA plates and incubated at $25^{\circ} \mathrm{C}$ for 3 days. Three replicates were performed for each of the selected isolates and the tests were repeated twice. Colony area (in square centimeters) was measured to compare mycelial, growth and the means for isolates were compared with Fisher's least significant difference (LSD) test $(7,8)$.

Conidial production test. Mung bean broth (MBB; $50 \mathrm{~g}$ of mung bean in 1 liter of $\mathrm{H}_{2} \mathrm{O}$ ) was used for the conidium production test. Five mycelial plugs ( $5 \mathrm{~mm}$ in diameter) from each of the isolate as described above were transferred individually to conical flasks, each containing $100 \mathrm{ml}$ of $\mathrm{MBB}$ for shake culture $\left(150 \mathrm{rpm}, 25^{\circ} \mathrm{C}\right.$, and 12-h photoperiod). Production of conidia was assessed by using a hemocytometer after 7 days of incubation, as previously described $(7,8)$. The conidial production of both carbendazimsensitive and -resistant isolates were compared using Fisher's LSD test. There were three replicates for each of the isolates, and the tests were repeated twice.

Perithecium production test. Wheat seed which had been autoclaved were used for the perithecium production test (7). Mycelial plugs $(5 \mathrm{~mm}$ in diameter) from each of the isolates, as described above, were inoculated onto autoclaved wheat seed of 'Wanmai22', a local planted wheat cultivar susceptible to FHB, and cultured at $25^{\circ} \mathrm{C}$ for 7 days. Then, the seed were covered with sterile wet sand and cultured in a humid chamber at $25^{\circ} \mathrm{C}$ with a 12-h photoperiod. Production of perithecia was assessed according to the previously study (7). There were 20 to 30 replicates (each seed as a replicate) for each of the isolates, and the tests were repeated three times.

Pathogenicity test. Wanmai22 was used for the pathogenicity test. The wheat plants were grown in polyethylene pots (diameter of $7.5 \mathrm{~cm}$, five plants per pot) containing a $2: 1(\mathrm{vol} / \mathrm{vol})$ mixture of peat and perlite. All of the experiments on wheat plants were performed with plants at Feekes growth scale 7.0 (second node visible next to last leaf visible) to 10.5.1 (beginning flowering). In field experiments conducted in 2013, pathogenicity was compared between the previously selected 10 carbendazim-sensitive and 10 carbendazim-resistant isolates as described above, using Fisher's LSD test. First, conidium suspensions of each isolate were prepared in $5 \% \mathrm{MBB}$ and adjusted to a concentration of $10^{5}$ spores/ml. Subsequently, $10 \mu \mathrm{l}$ of conidial suspension of each isolate was injected into the middle of a spikelet, and at least 20 replicate spikes (each plant as a replicate) were inoculated. Control wheat spikes were inoculated with the same volumes of 5\% MBB. All of the treated plants were incubated under the same field conditions. The severity of scabbed wheat heads was calculated according to a previous study to compare the pathogenicity of these selected isolates (7). There were more than 20 replicates for each of the isolates and the experiment was repeated twice.

Isolation of genomic DNA. Potato sucrose broth (PSB) was used to obtain mycelium of $F$. asiaticum for DNA extraction. Genomic DNA was extracted from approximately $0.5 \mathrm{~g}$ of mycelia of all the carbendazim-resistant and 10 arbitrarily selected carbendazim-sensitive $F$. asiaticum isolates which were grown in PSB at $25^{\circ} \mathrm{C}$ for 4 days. The DNA extraction method was adapted by a modified cetyltrimethylammonium bromide method according to a previous study (22). The genomic DNA was precipitated with approximately 2.5 volumes of ethanol and $1 / 10$ volume of $3 \mathrm{M}$ sodium acetate, washed twice with $70 \%$ ethanol, and dissolved in 50 to $100 \mu \mathrm{l}$ of Tris-EDTA buffer $(10 \mathrm{mM}$ Tris- $\mathrm{HCl}$ and $1 \mathrm{mM}$ EDTA, $\mathrm{pH}$ 7.4) after drying.

Cloning and sequencing of $\beta_{2}$-tubulin gene in carbendazimsensitive and -resistant isolates of $\boldsymbol{F}$. asiaticum. Based on the sequence information of $\beta_{2}$-tubulin gene in $F$. asiaticum, the polymerase chain reaction (PCR) primer pairs $\beta_{2} \mathrm{~F} 5^{\prime}$-ACCAGA CCCAAAGACACCTCA- $3^{\prime}$ and $\beta_{2} \mathrm{R} \quad 5^{\prime}$-GGCTTTGCGAAG ATGTATGTAGA-3' were designed and used for amplification of the whole fragment of the $\beta_{2}$-tubulin gene. PCR reaction mixtures contained total DNA $(25 \mathrm{ng} / \mu \mathrm{l}), 1.5 \mathrm{mM} \mathrm{MgCl} 2,200 \mu \mathrm{M}$ each dNTP, and $2.5 \mathrm{U}$ of LA Taq DNA polymerase. PCR reactions were performed in a DNA Engine System SEDI (Wealtech, USA) programmed for $2.5 \mathrm{~min}$ at $94^{\circ} \mathrm{C}$; followed by 40 cycles of $0.5 \mathrm{~min}$ at $94^{\circ} \mathrm{C}, 1 \mathrm{~min}$ at $52^{\circ} \mathrm{C}$, and $1.5 \mathrm{~min}$ at $72^{\circ} \mathrm{C}$; a final extension for $8.5 \mathrm{~min}$ at $72^{\circ} \mathrm{C}$; and holding at $4^{\circ} \mathrm{C}$. PCR products were separated by electrophoresis on $1.5 \%$ agarose gels in $40 \mathrm{mM}$ Tris-acetate $(\mathrm{pH}$ 8.0) and $1 \mathrm{mM}$ EDTA buffer.

The PCR products were purified using microspin columns and the purified products were ligated to the PMD19-T Vector*1 (D104A; TaKaRa), as instructed by the manufacturer, and transformed into competent Escherichia coli (DH5 $\alpha$ ) cells. Transformants were selected on Luria-Bertani (LB) agar plates containing ampicillin (AMP), isopropylthio- $\beta$-D-galactoside, and 5bromo-4-chloro-3-indolyl- $\beta$-D-galactoside. Individual clones were used to inoculate LB broth containing AMP and grown overnight at $37^{\circ} \mathrm{C}$ with shaking. Recombinant plasmids were purified and confirmed that the inserts were of the desired size using H. Q. \& Q. Plasmid Mini Kit (Anhui U-Gene Biotechnology Co., Ltd.) and the pUC19 Vectors (TaKaRa), respectively, according to the manufacturers' instructions. Plasmids were sequenced in Shanghai Sangon Biological Engineering Technology \& Services Co., Ltd. After sequencing, the base sequences were translated to amino acid sequences with National Center for Biotechnology Information GenBank yeast mitochondrial code.

Data analysis. Data from repeated experiments were combined for analysis because variances between experiments were homogeneous. The data were analyzed by analysis of variance using SAS 9.3 (SAS Institute, Inc., Cary, NC) to test for significant differences between treatment means. Fisher's LSD test was used to determine significant differences in the biological properties between the selected carbendazim-sensitive and -resistant isolates, as previously described (7).

\section{Results}

Sensitivity of field $\boldsymbol{F}$. asiaticum isolates to carbendazim. Of the 899 isolates tested, 74 isolates were resistant to carbendazim from all the sampled sites of Anhui Province, with an overall carbendazim resistance frequency of $8.2 \%$. Among these 74 isolates, the numbers of LR, MR, and HR were 1, 68, and 5, respectively. Overall, the frequency of resistance was significantly different in different regions of Anhui Province according to the $t$ test (hypoth- 
esis test of percentages): the highest frequencies of carbendazim resistance were observed in Bengbu (16.8\%) and Chuzhou $(12.8 \%)$. By contrast, the lowest frequencies were detected in Hefei $(0.0 \%)$ and An'qing (1.4\%) (Table 1). Carbendazim resistance distribution was board throughout the Province but incidence varied depending on the sampled sites.

Characterization of carbendazim-sensitive and -resistant isolates. The selected carbendazim-resistant isolates were able to grow normally on the PSA plates amended with carbendazim at 1.4 $\mu \mathrm{g} / \mathrm{ml}$ with thick aerial mycelium but the selected field carbendazim-sensitive isolates' growth was completely inhibited (data not shown). Most of the carbendazim-resistant isolates did not show changes on mycelial growth compared with the carbendazimsensitive isolates on fungicide-free PSA plates, indicating that the main fitness parameters of the carbendazim-resistant isolates were not significantly affected by resistance.

The ability to produce conidia for the selected field (sensitive or resistant) was compared after a 7-day shake culture in MBB. The results suggested that all the selected carbendazim-sensitive and -resistant isolates could produce conidia equally. However, all the selected isolates exhibited different capacities for producing conidia, and resistance did not seem to affect the conidial production in the carbendazim-resistant isolates (Table 2).

All of the selected carbendazim-sensitive and -resistant isolates produced perithecia and the mature ascospores from the perithecia could be observed after a period of time (about 20 to 30 days after inoculation in sands), except for carbendazimresistant isolate FY02R; however, the ability to produce perithecia of the selected isolates was not affected by carbendazim resistance (Table 2).

The average FHB severity (recorded as the mean values) was compared 3 weeks after inoculation in the field. There were no significant differences between the selected field carbendazimsensitive and -resistant isolates (Table 2). Therefore, it could be concluded that, in most of the cases, the resistance to carbendazim did not affect the pathogenicity of $F$. asiaticum populations.

Table 1. Number of isolates of Fusarium asiaticum sensitive or resistant to carbendazim found in major-wheat growing areas throughout Anhui province of China from 2010 to 2012

\begin{tabular}{|c|c|c|c|c|c|c|c|c|}
\hline \multirow[b]{3}{*}{ Sites } & \multicolumn{8}{|c|}{ Sample year ${ }^{z}$} \\
\hline & \multicolumn{2}{|c|}{2010} & \multicolumn{2}{|c|}{2011} & \multicolumn{2}{|c|}{2012} & \multicolumn{2}{|c|}{ Overall (by location) } \\
\hline & $N$ & Freq $(\%)$ & $N$ & Freq $(\%)$ & $N$ & Freq $(\%)$ & $N$ & Freq $(\%)$ \\
\hline Suzhou & $1(20)$ & $5.0 \mathrm{~b} \mathrm{D}$ & $1(28)$ & $3.6 \mathrm{c} \mathrm{E}$ & $5(43)$ & 11.6 a C & $7(91)$ & 7.6 \\
\hline Huaibei & $3(30)$ & $10.0 \mathrm{a} B$ & $1(21)$ & $4.8 \mathrm{~b} \mathrm{D}$ & $2(40)$ & $5.0 \mathrm{~b} \mathrm{G}$ & $6(91)$ & 6.6 \\
\hline Bozhou & $1(23)$ & $4.3 \mathrm{cD}$ & $1(18)$ & $5.6 \mathrm{~b} \mathrm{D}$ & $2(22)$ & $9.1 \mathrm{a} \mathrm{E}$ & $4(63)$ & 6.3 \\
\hline Fuyang & $3(37)$ & $8.1 \mathrm{~b} \mathrm{C}$ & $2(26)$ & $7.7 \mathrm{~b} \mathrm{C}$ & $4(38)$ & 10.5 a D & $9(101)$ & 8.9 \\
\hline Huainan & $4(47)$ & 8.5 a C & $1(28)$ & $3.6 \mathrm{c} \mathrm{E}$ & $2(32)$ & $6.3 \mathrm{~b} \mathrm{~F}$ & 7 (107) & 6.5 \\
\hline Bengbu & $4(28)$ & $14.3 \mathrm{~b} \mathrm{~A}$ & $2(22)$ & $9.1 \mathrm{c} \mathrm{B}$ & $12(57)$ & $21.1 \mathrm{a} \mathrm{A}$ & 18 (107) & 16.8 \\
\hline Chuzhou & $3(22)$ & $13.6 \mathrm{a} A$ & $3(26)$ & $11.5 \mathrm{~b} \mathrm{~A}$ & $8(61)$ & $13.1 \mathrm{a} \mathrm{B}$ & 14 (109) & 12.8 \\
\hline Lu'an & $1(26)$ & $3.8 \mathrm{c} \mathrm{D}$ & $3(28)$ & 10.7 a A & $4(48)$ & $8.3 \mathrm{~b} \mathrm{E}$ & 8 (102) & 7.8 \\
\hline Hefei & 0 (19) & $0.0 \mathrm{a} \mathrm{E}$ & $0(10)$ & $0.0 \mathrm{a} \mathrm{H}$ & $0(28)$ & $0.0 \mathrm{a} \mathrm{H}$ & $0(57)$ & 0.0 \\
\hline Anqing & $0(33)$ & $0.0 \mathrm{c} \mathrm{E}$ & $0(18)$ & $2.6 \mathrm{~b} \mathrm{G}$ & $1(20)$ & $5.0 \mathrm{a} \mathrm{G}$ & $1(71)$ & 1.4 \\
\hline
\end{tabular}

${ }^{\mathrm{z}}$ Number $(N)$ of field resistant isolates is listed and the total number of tested isolates is given in parentheses. Isolates that showed normal growth at 1.4 $\mu \mathrm{g} / \mathrm{ml}$ were considered resistant, whereas the completely inhibited ones were considered sensitive. The frequency of resistance (Freq) was calculated using the following formula: resistance frequency $=$ (number of carbendazim-resistant isolates/number of sampled isolates) $\times 100 \%$. Percentages followed by the same letter were not different according to the $t$ test (hypothesis test of percentages, $P=0.05$ ). Please note that the analysis of variance of the resistance frequency within the same region from 2010 to 2012 was compared (lowercase letters, $P=0.05$ ) and the analysis of variance of the resistance frequency within the same year in different regions was compared (uppercase letters, $P=0.05$ ) according to the $t$ test (hypothesis test of percentages, $P=0.05$ ).

Table 2. Comparison of some important biological properties between field carbendazim-sensitive and -resistant isolates

\begin{tabular}{|c|c|c|c|c|c|}
\hline Isolates $^{\mathbf{v}}$ & $\begin{array}{l}\text { Resistance phenotypes } \\
\text { of the isolates }{ }^{w}\end{array}$ & $\begin{array}{c}\text { Colony area } \\
\left(\mathbf{c m}^{2}\right)^{\mathrm{x}}\end{array}$ & $\begin{array}{c}\text { Conidia production } \\
\text { capacity }\left(10^{6} / \mathrm{ml}\right)^{\mathrm{x}}\end{array}$ & $\begin{array}{c}\text { FHB severity } \\
(\%)^{\mathrm{y}}\end{array}$ & $\begin{array}{c}\text { Perithecial } \\
\text { capacity }^{\mathbf{z}}\end{array}$ \\
\hline CZ02S & $\mathrm{S}$ & $36.5 \mathrm{a}$ & $1.03 \mathrm{ab}$ & $36.65 \pm 5.16 \mathrm{a}$ & + \\
\hline CZ05S & $\mathrm{S}$ & $36.5 \mathrm{a}$ & $0.77 \mathrm{c}$ & $36.36 \pm 4.18 \mathrm{a}$ & ++ \\
\hline FY01S & $\mathrm{S}$ & $34.2 \mathrm{ab}$ & $1.16 \mathrm{a}$ & $37.01 \pm 4.83 \mathrm{a}$ & + \\
\hline FY02S & $\mathrm{S}$ & $36.6 \mathrm{a}$ & $0.53 \mathrm{de}$ & $33.65 \pm 4.53 \mathrm{a}$ & +++ \\
\hline FY04S & $\mathrm{S}$ & $37.1 \mathrm{a}$ & $0.86 \mathrm{bc}$ & $35.08 \pm 4.64 \mathrm{a}$ & + \\
\hline FY06S & $\mathrm{S}$ & $32.9 \mathrm{~b}$ & $1.03 \mathrm{ab}$ & $32.55 \pm 6.47 \mathrm{a}$ & ++ \\
\hline YS02S & $\mathrm{S}$ & $35.3 \mathrm{a}$ & $1.38 \mathrm{a}$ & $35.53 \pm 5.62 \mathrm{a}$ & + \\
\hline YS03S & $\mathrm{S}$ & $36.8 \mathrm{a}$ & $0.44 \mathrm{e}$ & $34.99 \pm 6.74 \mathrm{a}$ & ++ \\
\hline LJ06S & $\mathrm{S}$ & $35.9 \mathrm{a}$ & $0.76 \mathrm{c}$ & $35.40 \pm 3.45 \mathrm{a}$ & +++ \\
\hline LJ11S & $\mathrm{S}$ & $37.4 \mathrm{a}$ & $1.31 \mathrm{a}$ & $33.68 \pm 4.18 \mathrm{a}$ & +++ \\
\hline CZ01R & MR & $36.5 \mathrm{a}$ & $0.79 \mathrm{c}$ & $34.64 \pm 3.21 \mathrm{a}$ & ++ \\
\hline CZ03R & MR & $36.7 \mathrm{a}$ & $0.50 \mathrm{e}$ & $36.42 \pm 5.17 \mathrm{a}$ & + \\
\hline FY02R & MR & $28.5 \mathrm{~b}$ & $1.01 \mathrm{ab}$ & $36.74 \pm 6.40 \mathrm{a}$ & - \\
\hline FY04R & MR & $29.7 \mathrm{c}$ & $0.76 \mathrm{c}$ & $37.12 \pm 4.46 \mathrm{a}$ & + \\
\hline FY09R & HR & $37.4 \mathrm{a}$ & $0.89 \mathrm{bc}$ & $34.58 \pm 4.07 \mathrm{a}$ & ++ \\
\hline YS06R & MR & $29.6 \mathrm{~b}$ & $0.40 \mathrm{e}$ & $38.16 \pm 4.19 \mathrm{a}$ & + \\
\hline YS11R & MR & $36.2 \mathrm{a}$ & $0.73 \mathrm{c}$ & $37.54 \pm 3.13 \mathrm{a}$ & ++ \\
\hline YS17R & MR & $36.9 \mathrm{a}$ & $1.03 \mathrm{ab}$ & $35.61 \pm 5.41 \mathrm{a}$ & ++ \\
\hline LJ13R & HR & $33.2 \mathrm{~b}$ & $0.46 \mathrm{de}$ & $33.12 \pm 3.88 \mathrm{a}$ & ++ \\
\hline LJ19R & MR & $36.7 \mathrm{a}$ & $1.18 \mathrm{a}$ & $33.68 \pm 5.17 \mathrm{a}$ & ++ \\
\hline
\end{tabular}

${ }^{v}$ The 10 carbendazim-sensitive and 10 carbendazim-resistant isolates were arbitrarily selected from the entire collection.

${ }^{\mathrm{w}} \mathrm{S}, \mathrm{MR}$, and HR represent sensitive, moderate resistance, and high resistance, respectively, to carbendazim.

${ }^{x}$ Lowercase letters indicate Fisher's least significant difference (LSD) test between the parental isolate and its JS399-19-resistant mutants within a column $(P=0.05)$.

${ }^{y}$ Figures for Fusarium head blight (FHB) were averages (with or without) \pm standard deviation.

${ }^{z}$ Symbols,,++++++ , and - indicate perithecia covering the wheat grain surface more than two-thirds, between one-third and two-thirds, less than one-third, and no perithecia, respectively. 
Genotypes of $\beta_{2}$-tubulin gene in the field carbendazimresistant $\boldsymbol{F}$. asiaticum isolates. The amplified $\beta_{2}$-tubulin gene, of approximately $2.5 \mathrm{~kb}$ in size, was obtained from genomic DNA of F. asiaticum. Individual amplified fragments were purified, cloned, and then sequenced. Comparison of the nucleotide sequence of the $\beta_{2}$-tubulin gene in F. asiaticum isolates revealed that five kinds of point mutations were present in the sequences of all the resistant isolates. Among these isolates, a change from phenylalanine (in one sensitive isolate) to tyrosine [TTT (Phe) $\rightarrow$ TAT (Tyr)] at codon $167(\mathrm{~F} 167 \mathrm{Y})$ was found in $66 \mathrm{MR}$ isolates out of the 74 carbendazim-resistant isolates. Five HR isolates expressed two kinds of point mutations in the $\beta_{2}$-tubulin gene, including GAG (Glu) $\rightarrow$ CTG (Leu) (two isolates) or GAG (Glu) $\rightarrow$ AAG (Lys) (three isolates) at codon 198 (E198L or E198K). There were an additional two MR isolates and one LR isolate containing the point mutation of TTC (Phe) $\rightarrow$ TAC (Tyr) (F200Y) and GAG (Glu) $\rightarrow$ CAG (Gln) (E198Q), respectively, in their $\beta_{2}$-tubulin gene. It was noticeable that the resistant isolates with differential resistance levels (LR, MR, and HR) exhibited different point mutations in the $\beta_{2}$-tubulin gene at codons 167,198 , or 200 (Table 2 ). It is suggested that a single point mutation at codons 167,198 , or 200 of the $\beta_{2}$-tubulin gene, resulting in substitution of amino acids, correlated with differential levels of resistance. In all, the frequencies of the five kinds of point mutations (F167Y, E198L, E198K, F200Y, and E198Q) in the $\beta_{2}$-tubulin gene conferring resistance to carbendazim among the resistant isolates were 89.2, 2.7, 4.1, 2.7, and $1.4 \%$, respectively (Fig. 1).

\section{Discussion}

Because most wheat cultivars planted in China are susceptible to FHB, fungicide application is the primary method to control this disease. The benzimidazole fungicide carbendazim has been used extensively for FHB control for more than 30 years. With the numerous applications of this fungicide, resistance to carbendazim in F. asiaticum populations has been increasing gradually year by year in China $(8,10,33)$. Carbendazim resistance has occurred in many fungal pathogens after 2 to 3 years of its use $(1,3,14,17$, 19,20,29). In this study, 899 F asiaticum isolates were collected throughout Anhui Province, and their sensitivity to carbendazim was determined. Of the 899 isolates, 74 were resistant to carbendazim, with an overall carbendazim resistance frequency of $8.2 \%$. Most of the carbendazim-resistant isolates exhibited similar ability in mycelial growth, conidial production, perithecium production, and pathogenicity when compared with the sensitive isolates. However, some field carbendazim-resistant isolates had decreased mycelial growth on PSA plates when compared with carbendazimsensitive isolates. From these data, it could be concluded that, at least in some cases, the mutation to carbendazim resistance may have an indirect effect on vegetative growth (Table 2). Taken together, it could be concluded that, in most of the cases, the resistance to carbendazim did not affect the mycelial growth, conidial production, perithecium production, and pathogenicity of F. asiaticum populations.

Previous studies have reported that mutations at Glu198Ala, Val, Gly, Phe200Tyr, and other codons of $\beta$-tubulin were responsible for the resistance to benzimidazole fungicides (1). Interestingly, a previous study demonstrated that point mutations at codons 198 and 200 of the target gene in parasitic nematodes also conferred resistance to benzimidazole nematicides, a veterinary medicine (16). However, recent studies have confirmed that the resistance to carbendazim in $F$. graminearum species complex is different from other fungal pathogens because there is another $\beta$-tubulin gene (now called $\beta_{2}$-tubulin) in which the point mutations are responsible for the resistance (6). There are two main differences. First, the point mutation of Glu198Leu at the $\beta$-tubulin gene conferring resistance to carbendazim is unique in the $F$. graminearum species complex and different from the point mutation of Glu198Gln in the same gene, conferring resistance to carbendazim (6). Second, the benzimidazole resistance in the other fungal pathogens is caused by point mutations in a $\beta$-tubulin that is highly identical to the $\beta_{1^{-}}$ tubulin of the $F$. graminearum species complex, whereas the carbendazim resistance has been confirmed to be caused by the point mutation in the $\beta$-tubulin gene (6). There were five different point mutation types in the $\beta$-tubulin gene of other fungal pathogens at the same codon responsible for the resistance to carbendazim, as follows: (i) the point mutation of Glu198Ala in Tapesia acuformis (1), T. yallundae (1), Penicillium expansum (14), Venturia inaequalis (14), Botrytis cinerea (17), Monilinia fructicola (19), and Helminthosporium solani (20), which are HR to carbendazim; (ii) the point mutation of Glu198Gln in T. acuformis (1), T. yalhundae (1), and $H$. solani $(1,20)$ which are LR to carbendazim; (iii) the point mutation of Glu198Gly in $V$. inaequalis (14), T. acuformis (1), and T. yalhundae (1) which are MR to carbendazim; (iv) the point mutation of Glu198Lys in T. yalhundae (1), T. acuformis (1), $P$. expansum (14), and $M$. fructicola (19) which are MR to carbendazim; and (v) the point mutation of Glu198Val in $P$. expansum (14) which is HR to carbendazim.

Among these resistant isolates, it could be concluded that point mutation at codon 167,198 , or 200 of the $\beta_{2}$-tubulin gene, resulting in substitution of amino acids, correlated with different levels of resistance; that there are five kinds of point mutations (F167Y, E198L, E198K, F200Y, and E198Q) in the $\beta_{2}$-tubulin gene causing the resistance to carbendazim; and that the frequencies of resistant isolates were $89.2,2.7,4.1,2.7$, and $1.4 \%$, respectively. To our knowledge, this is the first report on the survey of carbendazim resistance and the point mutation in $\beta_{2}$-tubulin gene conferring resistance to carbendazim of $F$. asiaticum populations in Anhui Province of China.

Based on monitoring of carbendazim resistance, the frequency of resistant $F$. asiaticum populations in the main wheat-production areas of Anhui Province increased steadily, and the efficacy of carbendazim against $F$. asiaticum greatly decreased during these years (10). In a sense, the efficacy of carbendazim in controlling FHB was reduced due to the heavy application of carbendazim that provided a strong selection pressure for resistant pathogen $F$. asiaticum populations in the field (33). Because of this high selection pressure leading to widespread resistance, it is imperative to identify alternative fungicides with different modes of action to manage FHB on wheat. Recently, the triazoles (ergosterol biosynthesis inhibitors) such as tebuconazole are becoming popular to control this disease in China because they are effective against FHB and used worldwide (7). The trizoles could not only inhibit mycelial growth but also manage the carbendazim resistance development (13). Moreover, application of trizole fungicides could effectively decrease the incidence of primary infection during the wheat flowering (13). Fludioxonil, which exhibits strong activity against mycelial growth, is also a suitable candidate fungicide for controlling FHB and is now popular in the United States (4). Recently, a newly developed cyanoacrylate fungicide, JS399-19 (experimental code), has been marked and widely used for FHB control in Anhui Prov-

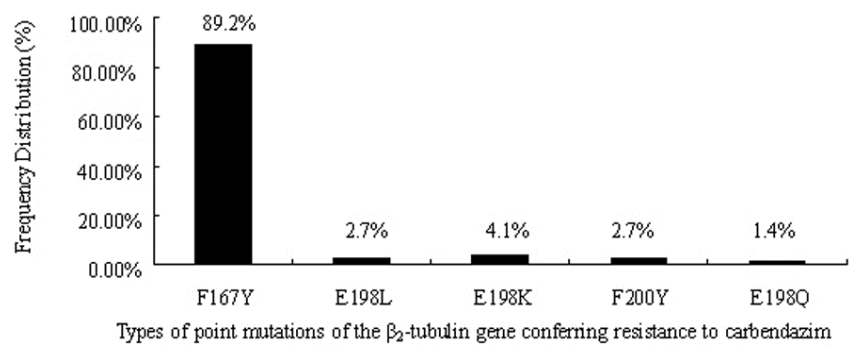

Fig. 1. Frequency distribution of point mutation types at codons 167, 198, or 200 of the $\beta_{2}$-tubulin gene causing resistance to carbendazim in the field carbendazimresistant Fusarium asiaticum isolates F167Y, E198L, E198K, F200Y, and E198Q, which are responsible for different levels of resistance to carbendazim. The carbendazim-resistant $F$. asiaticum isolates had point mutations of TTT (Phe) $\rightarrow$ TAT (Tyr), GAG (Glu) $\rightarrow$ CTG (Leu), GAG (Glu) $\rightarrow$ AAG (Lys), TTC (Phe) $\rightarrow$ TAC (Tyr), and GAG (Glu) $\rightarrow$ CAG (Gln) (E198Q) in the $\beta_{2}$-tubulin gene, respectively. Numbers 167,198 , and 200 in the abbreviations represented the codons of 167,198 , and 200 of the $\beta_{2}$-tubulin gene in $F$. asiaticum. 
ince (9). It has excellent efficacy against this disease and strong power for the management of carbendazim resistance (9). However, all these fungicides mentioned above should not be solely used because the resistance to these fungicides has been reported in other systems. Presumably, tank-mixing the fungicide JS399-19 with trizole fungicides or fludioxonil will be effective in controlling FHB because cross-resistance between the fungicide JS399-19 and these fungicides is absent (7). Also, in order to delay the development of resistance, the sensitivity of $F$. asiaticum populations to all of these mentioned fungicides should be monitored year by year.

\section{Acknowledgments}

This study was sponsored by (i) 2014 Science and Technological Fund of Anhui Province for Outstanding Youth (1408085J02); (ii) Anhui Provincial Scientific and Technological Project (1301032138); (iii) the Key Project in the National Science and Technology Pillar Program during the Twelfth Five-Year Plan Period (number 2012BAD04B09); (iv) Special Fund for Agro-Scientific Research in the Public Interest from the Ministry of Agriculture, China (201303023); (v) National Natural Science Foundation of China (31201550 and 31272073); (vi) Innovation Team of Anhui Academy of Agricultural Sciences (12C1105, 13C1113 and 14C1111); and (vii) 2014 Dean Youth Innovation Fund of Anhui Academy of Agricultural Sciences (14B1152).

\section{Literature Cited}

1. Albertini, C., Gredt, M., and Leroux, P. 1999. Mutations of the b-tubulin gene associated with different phenotypes of benzimidazole resistance in the cereal eye spot fungi Tapesia yallundae and Tapesia acuformis. Pestic. Biochem. Physiol. 64:17-23.

2. Bai, G., and Shaner, G. 1994. Scab of wheat: Prospects for control. Plant Dis. 78:760-766.

3. Bollen, G. J., and Scholten, G. 1971. Acquired resistance to benomyl and some other systemic fungicides in a strain of Botrytis cinerea in cyclamen. Neth. J. Plant Pathol. 77:83-90.

4. Broders, K. D., Lipps, P. E., Paul, P. A., and Dorrance, A. E. 2007. Evaluation of Fusarium graminearum associated with corn and soybean seed and seedling disease in Ohio. Plant Dis. 91:1155-1160.

5. Carter, J. P., Rezanoor, H. N., Holden, D., Desjardins, A. E., Plattner, R. D., and Nicholson, P. 2002. Variation in pathogenicity associated with the genetic diversity of Fusarium graminearum. Eur. J. Plant Pathol. 108:573583

6. Chen, C.-J., Yu, J.-J., Bi, C.-W., Zhang, Y.-N., Xu, J.-Q., Wang, J.-X., and Zhou, M.-G. 2009. Mutations in a $\beta$-tubulin confer resistance of Gibberella zeae to benzimidazole fungicides. Phytopathology 99:1403-1411.

7. Chen, Y., Li, H., Chen, C., and Zhou, M. 2008. Sensitivity of Fusarium graminearum to fungicide JS399-19: In vitro determination of baseline sensitivity and the risk of developing fungicide resistance. Phytoparasitica 36:326-337.

8. Chen, Y., Wang, J. X., Zhou, M. G., Chen, C. J., and Yuan, S. K. 2007. Vegetative compatibility of Fusarium graminearum isolates and genetic study on their carbendazim-resistance recombination in China. Phytopathology 97:1584-1589.

9. Chen, Y., Wang, W.-X., Zhang, A.-F., G, C.-Y., Zhou, M.-G., and Gao T.-C. 2011. Activity of the Fungicide JS399-19 against Fusarium head blight of wheats and the risk of resistance. Agric. Sci. China 10:1906-1913.

10. Chen, Y., Zhang, A.-F., Gao, T.-C., Zhang, Y., Wang, W.-X., Ding, K.-J., Chen, L., Sun, Z., Fang, X.-Z., and Zhou, M.-G. 2012. Integrated use of pyraclostrobin and epoxiconazole for the control of Fusarium head blight of wheat in Anhui Province of China. Plant Dis. 96:1495-1500.

11. Chen, Y., and Zhou, M.-G. 2009. Characterization of Fusarium graminearum isolates resistant to both carbendazim and a new fungicide JS399-19. Phytopathology 99:441-446.

12. Homdork, S., Fehrmann, H., and Beck, R., 2000. Influence of different storage conditions on the mycotoxin production and quality of Fusarium-infected wheat grain. J. Phytopathol. 148:7-15.
13. Klix, M. B., Verreet, J. A., and Beyer, M. 2007. Comparison of the declining triazole sensitivity of Gibberella zeae and increased sensitivity achieved by advances in triazole fungicide development. Crop Prot. 26:683-690.

14. Koenraadt, H., Somerville, S. C., and Jones, A. L. 1992. Characterization of mutations in the beta-tubulin gene of benomyl-resistant field strains of Venturia inaequalis and other plant pathogenic fungi. Phytopathology 82:13481354

15. Koizumi, S., Kageyama, K., and Hyakumachi, M. 2008. Molecular characterization of the Fusarium graminearum species complex in Japan. Phytopathology 98:159-166.

16. Kwa, M. S. G., Veenstra, J. G., van Dijk, M., and Roos, M. H. 1995. $\beta$ Tubulin genes from the parasitic nematode Haemonchus contortus modulate drug resistance in Caenorhabditis elegans. J. Mol. Biol. 246:500-510.

17. Luck, J. E., and Gillings, M. R. 1995. Rapid identification of benomyl resistant strains of Botrytis cinerea using the polymerase chain reaction. Mycol. Res. 99:1483-1488.

18. Ma, Z., and Michailides, T. 2005. Advances in understanding molecular mechanisms of fungicide resistance and molecular detection of resistant genotypes in phytopathogenic fungi. Crop Prot. 24:853-863.

19. Ma, Z., Yoshimura, M., and Michailides, T. J. 2003. Identification and characterization of benzimidazole resistance in Monilinia fructicola from stone fruit orchards in California. Appl. Environ. Microbiol. 69:7145-7152.

20. McKay, G. J., and Cooke, L. R. 1997. A PCR-based method to characterize and identify benzimidazole resistance in Helminthosporium solani. FEMS Microbiol. Lett. 152:371-378.

21. O'Donnell, K., Ward, T. J., Geiser, D. M., Kistler, H. C., and Aokid, T. 2004. Genealogical concordance between the mating type locus and seven other nuclear genes supports formal recognition of nine phylogenetically distinct species within the Fusarium graminearum clade. Fungal Genet. Biol. 41:600-623

22. Park, Y. S., Choi, I. D., Kang, C. M., Ham, M. S., Kim, J. H., Kim, T. H. Yun, S. H., Lee, Y. W., Chang, H. I., Sung, H. C., and Yun, C. W. 2006. Functional identification of high-affinity iron permeases from Fusarium graminearum. Fungal Genet. Biol. 43:273-282.

23. Snijders, C. H. A. 1990. Fusarium head blight and mycotoxin contamination of wheat, a review. Neth. J. Plant Pathol. 96:187-198.

24. Starkey, D. E., Ward, T. J., Aoki, T., Gale, L. R., Kistler, H. C., Geiser, D. M., Suga, H., Tóth, B., Varga, J., and O’Donnell, K. 2007. Global molecular surveillance reveals novel Fusarium head blight species and trichothecene toxin diversity. Fungal Genet. Biol. 44:1191-1204.

25. Stoyan, R. P., Simon, G. E., Martin, C. H., and Peter, J. 2003. Strategies for the control of Fusarium head blight in cereals. Eur. J. Plant Pathol. 109:731742 .

26. Suga, H., Karugia, G. W., Ward, T., Gale, L. R., Tomimura, K., Nakajima, T., Miyasaka, A., Koizumi, S., Kageyama, K., and Hyakumachi, M. 2008 Molecular characterization of the Fusarium graminearum species complex in Japan. Phytopathology 98:159-166.

27. Tóth, B., Mesterházy, A., Horváth, Z., Bartók, T., Varga, M., and Varga, J. 2005. Genetic variability of central European isolates of the Fusarium graminearum species complex. Eur. J. Plant Pathol. 113:35-45.

28. Vesonder, R. F., and Hesseltine, C. W., 1980. Vomitoxin: Natural occurrence on cereal grains and significance as a refusal and emetic factor to swine. Process Biochem. 16:12-15.

29. Wicks, T. 1974. Tolerance of the apple scab fungus to benzimidazole fungicides. Plant Dis. Rep. 58:886-889.

30. Yin, Y., Liu, X., Li, B., and Ma, Z. 2009. Characterization of sterol demethylation inhibitor-resistant isolates of Fusarium asiaticum and F. graminearum collected from wheat in China. Phytopathology 99:487-497.

31. Yuan, S., and Zhou, M. 2005. A major gene for resistance to carbendazim, in field isolates of Gibberella zeae. Can. J. Plant Pathol. 27:58-63.

32. Zhang, J. B., Li, H. P., Dang, F. J., Qu, B., Xu, Y. B., Zhao, C. S., and Liao, Y. C. 2007. Determination of the trichothecene mycotoxin chemotypes and associated geographical distribution and phylogenetic species of the Fusarium graminearum clade from China. Mycol. Res. 111:967-975.

33. Zhou, M. G., Ye, Z. Y., and Liu, J. F. 1994. Progress of fungicide resistance. J. Nanjing Agric. Univ. 17:33-41 